\title{
Effect of Explicit Spoken Grammar Instruction on Raising Pre-Intermediate Iranian EFL Learners' Competence
}

\author{
Bahram Mowlaie (Correspondence author) \\ Department of Persian Literature and Foreign Languages, Islamic Azad University \\ South Tehran Branch, Tehran, Iran \\ E-mail: mowlaiebahram@gamil.com \\ Mona Mirzaei \\ Department of Persian Literature and Foreign Languages, Islamic Azad University \\ South Tehran Branch, Tehran, Iran \\ E-mail: monamirzaei1680@gmail.com
}

Received: December 30, 2016

doi:10.5296/gjes.v3i1.10531
Accepted: February 22, 2017 Published: May 10, 2017

URL: https://doi.org/10.5296/gjes.v3i1.10531

\begin{abstract}
The present study aimed at investigating the effect of explicit instruction of four main spoken grammar features of heads, tails, progressive past tense, and ellipsis on raising EFL learners' awareness of them. The main impetus came from the fact that these features are usually ignored in ELT textbooks because nearly all grammatical points are restricted to written grammar. To this end, 23 female EFL learners in pre-intermediate level whose homogeneity was confirmed using KET test, were assigned to an experimental group. A pretest was conducted to determine their current level awareness of the spoken features aforementioned. A posttest was administered after 10 sessions of awareness-raising oriented instruction. The data analysis showed that it is both possible and potentially desirable to apply explicit instruction to raise learners' awareness of aspects of native speaker spoken grammar to EFL learners. The study can have educational implications for language teachers and learners in EFL context.
\end{abstract}

Keywords: Corpus, Ellipsis, Explicit teaching, Heads, Spoken grammar features, Tails 


\section{Introduction}

An interest in the subject of spoken language is not a novel development. Palmer and Blandford published 'A Grammar of Spoken English' as early as 1924, but by the emergence of computerized corpora the quality of evidence of spoken grammar, available to linguists, has remarkably improved. Despite the fact that the advent of sizeable computer corpora has made such research feasible for the first time, the grammar of conversation has remained as the Cinderella component until recently (Biber et al., 1999). This can be postulated to be even more conspicuous in the foreign language context like Iran. A point emphasized by Carter, Hughes and McCarthy (1998) is that work on spoken grammar is in its infancy and needs to be more clearly described. The high frequency of these features in the native speakers' interaction seems to be sine qua non of these features that makes them indispensable (Carter \& McCarthy, 1995).

Whereas language course books as well as reference books claim to be offering 'real English' to the learners, it might be argued that the types of grammar which aim to encourage the use of the spoken language still have their root in descriptions of written English grammar and have failed to include major features of the grammar of spoken form (Carter \& McCarthy, 1995). Thus, one of the inevitable consequences is that 'correct grammar' is associated with 'correct grammar' as represented in the written form of language; and that a great deal of perfectly normal utterances of native English speakers consequently come to be considered as 'ungrammatical' (Carter, Hughes, \& McCarthy, 1998). As a result, there are prejudgments that many of the grammatical features of speech evident in every day conversations are simply 'wrong'. As Carter and McCarthy believe, such a view of grammar is irrational and needs to be modified.

Considering all these, the main purpose of this paper is to highlight the point that certain grammatical forms, revealed by corpus- based analysis of spoken English, can enable a wider range of language uses which, as McCarthy and Carter (1995) note, are in line with the goals of most communicative teaching projects.

In order to acquire a good grasp of spoken English, some differences between spoken and written forms need to be clarified. However, as emphasized by Willis (2003), it is essential to make it clear that the difference between them is due to the different functions they fulfil. Having this notion in mind, some of the most common differences are uneven distribution of word classes, untidy and additive nature of spoken language.

According to Biber et al. (1999), the uneven distribution of basic word classes such as nouns, adjectives, and verbs across registers in the spoken English might be due to the interpersonal nature of conversation. Untidy nature of spoken language is also discernable in written transcript of spoken language; because it does not tell us exactly what it means, we are required to fill the gap using the context (Willis, 2003). Finally, according to Willis, spoken language is constructed bit by bit by the speaker to gradually complete or clarify the intended communicative picture. The additive feature is important because it can enable the listener to keep the bits of information in their mind and modify the collection with the oncoming information to finally reach the desired and intended communicative purpose. It is the distinct 
status of spoken grammar that makes Biber et al. (1999, p. 18) assert that features of written standard should not be imposed on the analysis of conversation.

The existence of the difference between written and spoken grammar, however, does not guarantee that these differences are transparent. In fact, as Biber et al. (1999) observed, many of the spoken grammatical features escape casual examination because of lack of transparency, and as a result they are overlooked in the teaching or studying of English grammar. Acknowledging the differences, Biber et al. state the point that speech is not as grammatically simple as has already been thought and that speakers in their interactions use a number of sophisticated grammatical forms. This is a fact that is contrary to the widely-held assumption that spoken form of language is simple.

To be familiar with some of the characteristics specific to spoken language, a selection of the main spoken grammar features investigated in this study is explained in detail.

\subsection{Heads}

According to our intention in conversation, we can sometimes change the regular order of words to put emphasis on particular parts of the sentence (Paterson, Caygill, \& Sewell, 2012). Therefore, "heads are displaced from their normal place and put at the front of sentences for this purpose. McCarthy (1998) underlines the discourse function of heads as "an act of consideration to the listener" in that they lead the listeners from familiar information towards a new entity. Thus, as heads foreground new information, they have a discoursal role. Carter and McCarthy (1995) emphasize that head fronting is common in everyday conversation. They regard left- placed or fronted items of such type as completely normal in conversational language and the 'right place' for the heads. As Paterson, Caygill, and Sewell (2012) explain, we often use heads in questions. Here is a question using normal word order:

Did you wear your new pink dress to Jo's party?

And here is the same question, with 'your new pink dress. at the front as a 'head':

Your new pink dress, did you wear it to Jo's party? (p. 80)

\subsection{Tails}

'Tails' are considered to be the mirror image of 'heads' which occupy the slot after the core constituents of a sentence (Timmis, 2003). The example that Aijmir (1989, p. 140) has provided is: "Well I think they very often are, these East Europeans", where the noun phrase in bold represents the tail. Carter and McCarthy (1997) stress that, tails constructions are not limited to specific regions and might be found in a number of contexts and by a range of different speakers. And as with heads, tails have both a discoursal and an interactive function. Among many roles that "tails" play, Carter and McCarthy mention reciprocity i.e. the practice of exchanging things with others for mutual benefit; informality, and coherence.

\subsection{Ellipsis}

Carter (1998, p. 45) observes, 'ellipsis' which normally involves the omission of the subject pronoun and auxiliary, is "pervasive and endemic" in conversational language. 
According to Cullen and Kuo (2007), although ellipsis can be easily recovered from the linguistic or situational context, its use and frequency in speech and writing is not the same. In particular, situational ellipsis, that is, the omission of items which are recoverable from the immediate situation, has been shown to be a feature associated with conversation, rather than written texts. They add, Situational ellipsis, the focus of this paper, particularly affects elements at the beginning of a turn or a clause, for example, subject pronouns and operators in questions, as the following examples from Biber et al. (1999, p. 158) illustrate:

Suppose I ought to tell you that, shouldn't I? (ellipsis of I)

Too old to change, aren't we? (ellipsis of we're)

So, no wonder that people had begun to watch him rather uneasily. (ellipsis of it's)

\subsection{Progressive Past Tense in Relation to Reported Speech}

Reporting speech is common in conversation and that there is some similarity between speech reporting in speech and writing. However, “....spoken data exhibit choices which are rarely, if ever, found in written text reports" (McCarthy, 1998, p. 158). Among the main features of reporting speech stated by McCarthy (1998, pp. 158-159), the use of the reporting verb in the past continuous is particularly interesting, both because it is very common (McCarthy refers to 136 instances in 1 million words of CANCODE) and because it is completely ignored in ELT materials. By study of the available data, a clear function is associated to this form of reporting speech and some probable judgments made about its occurrence in particular genres: "The past -ing form reports in the CANCODE corpus are genre- restricted and seem to belong to more general, non-narrative, casual, conversational contexts where they seem to signal topic management... and contrast with the 'focuson-words-uttered' function of past simple reports" (McCarthy, 1998, pp. 161-162). Here is an example: He was telling me that they'd died of the frost or something (Biber et al., 1999, p. 1120). This is in contrast with what EFL learners are limited in their exposure to this tense in their course books. In most of the course books, this tense is defined as a verb form consisting of an auxiliary 'be' in the past tense followed by a 'present participle' and used especially to indicate that an action or event was incomplete or in progress at a point of reference in the past (Swan, 1995).

As discussed so far, while corpus data have been of great help in introducing the features found in native speakers' speech, these features and their use and appropriate context have rarely been inserted into ELT textbooks (McCarthy \& Carter, 1995). More importantly, some features particularly heads, tails, ellipsis and progressive past tense which constitute main part of native speaker spoken grammar have been extensively, if not totally, ignored in ELT textbooks. This fact can be seen clearly in the foreign language context of Iran and even more so due to lack of tourists and the absence of any possibility of face to face interaction with English speakers. Therefore, the grammar types EFL learners confront in their course books are not the ones seen in native speaker speech but rather the ones mostly observed in their written language. The result is that, after some years of learning speaking, learners come to write well rather than to speak well! 


\section{Macrothink}

Global Journal of Educational Studies

ISSN 2377-3936

2017, Vol. 3, No. 1

Thus, in order to compensate for the absence of main features of native speakers' speech in ELT textbooks, the section below follows two significant purposes. First, it intends to underline the importance of having learners become aware of the existence of such features; and second, to emphasize applying approaches whose focus is on raising learners' awareness using strategies such as explicit instruction and noticing.

\subsection{Language Awareness and Explicit Knowledge}

Although some researchers favor "subliminal learning", Schmidt (1990) states that one cannot learn a foreign language, or anything else for that matter, only through subliminal perception. He proposes that explicit instruction may play a significant role in making learners notice features they do not come to notice otherwise. Aligned with Schmidt, Ellis (1997) states that instruction can draw learners' attention to items they may not otherwise notice. Schmidt (1994) claims that language learning is mainly a conscious process, that the role of unconscious knowledge has been exaggerated and that consciousness is a prerequisite for dealing with 'novel information, novice behavior and learning' (p. 138). As a result, consciousness is a necessary factor for noticing features and structures of a language.

Many researchers advocate Schmidt's (1994) view that consciousness is important in developing one's language (Bialystok, 1978; Krashen, 1985; Sharwood, 1981). However, the terms they use for conveying the fact that learners should be provided with chances to notice features of a language might differ. Some of the widely-used terms are focus-on-form (Fotos, 1994); consciousness-raising (Ellis, 1994; Fotos, 1994; Nitta \& Gardner, 2005; Yule, 1986); and input-enhancement (Sharwood, 1981).

Despite the importance of spoken language generally, and spoken grammar specifically, the main focus has been on syllabus or corpus design so that the instruction of spoken grammar features can become possible. There is a gap concerning measuring the effect of explicit instruction on raising learners' awareness of spoken grammar features. Considering this fact, the main purpose of the present study is to investigate whether the explicit instruction of these features using the corpora materials can possibly contribute to raising learners' awareness of these properties. Thus, this research aims to bring the notion of 'spoken grammar' to the attention of not only EFL teachers but also of EFL learners who have been misled into associating the grammar of native speakers' speech with the one they have encountered in their course books. To this end, the following research question is posed: Does explicit instruction of spoken grammar features of heads, tails, progressive past tense and ellipsis have any significant effect on raising EFL pre- intermediate learners' awareness of these features?

\section{Method}

\subsection{Participants}

The participants in this study were 23 female EFL learners aged from 14 to 22 years, who were selected from an English Language Institute in one of the cities near Tehran, the capital city. They had learned English for about four years in Communicative Language Teaching (CLT), and Direct Method (DM). Most of them had started learning English in the same 
institute and they befitted from the same method of education, the same teachers, and the same course books. However, to make sure that the participants were homogeneous, a general proficiency test (KET, 2014) was administered at the beginning of the term (the 3rd session) by the researchers.

\subsection{Instruments}

The first instrument used in this study was Key English Test (KET). It is one of the widely used tests to determine the general knowledge of Standard English. The exam tests all four English language skills - reading, writing, listening and speaking and it consists of three sections: Reading and Writing - 70 minutes; Listening - 25 minutes and Speaking - 8-10 minutes with the Reading and Writing paper constituting $50 \%$ and Listening and Speaking parts each $25 \%$ of the total marks. The speaking test is comprised of two parts conducted face to face with two examiners. To pass the exam, a total of 70 marks out of 100 across three papers are needed.

A pre- and post- test were the second instrument used in this study (See Appendix). The pre-test which aimed to identify the learners' current level of awareness of spoken grammar features of heads, tails, progressive past tense and ellipsis was in the form of a conversation designed by the researchers after consulting with certain professors and experts in TEFL field and in particular with Timmis, a reader at Nottingham University and a pioneer of syllabus design for teaching spoken grammar. However, all parts containing the features previously mentioned, were taken out of two books: one from "A handbook of spoken grammar" by Paterson, Caygill, and Sewell (2012) which is based on recent corpus research, and the other from "Longman grammar of spoken and written English" by Biber et al. (1999) which is based on Longman Corpus. As a result, the only thing the researchers did was designing the features in the form of a conversation. The learners were required to identify the four features mentioned previously by underlining them in the conversation. It is worth noting that in order to rule out any possibility of learners being unable to identify the features due to not knowing the names of the features rather than not having any knowledge of them, the researchers provided short definitions or descriptions of heads, tails, progressive past tense and ellipsis on the first page of the pre-test.

The post- test was identical to the pre-test with a small difference: the definitions of the features on the first page were omitted by the researchers. The reason for this change was that, since the learners had to be checked after treatment in terms of raising their awareness, the definitions as a source of help in identifying the features needed to be omitted.

\subsection{Procedure}

As the first step, the KET exam was administered to the 23 participants to determine their level of proficiency. After making sure of their homogeneity, they were all assigned to the experimental group. In the next step, the designed pre-test, mentioned before, was administered to the participants to check their awareness of spoken grammar features of heads, tails, progressive past tense and ellipsis before receiving any instruction. The results of this test in the form of the total frequency of each of the features identified by the participants as well as their mean score were kept by the researchers to be compared with 
post- test results later on.

The first session of the treatment started with a brief comparison of spoken and written language in general during which the learners were asked to talk about some of the differences if they knew any. The discussion continued until the subject of spoken grammar and its difference with grammar of written language was raised. The learners appeared to know nothing of the differences of interest in the current inquiry when the teacher provided them with some features common in native speakers' speech.

Instruction of heads as the first of four features which were the focus of this study, started in the second session. An explanation of this feature was followed by some examples and practices. This was followed by showing to the learners some parts of movies with heads featured in them and asking them to detect the occurrence of heads in them. This activity aimed to make the use of head and other features of interest look as authentic as possible. The learners were then asked to provide some similar examples of the use of heads in their first language (Persian) to make sure they had fully comprehended the meaning as well as the feature's application. The third session was devoted to a brief review as well as a detailed practice of heads. In the practice phase, in which some texts were distributed to the participants, they were required to detect whether the feature of head was present in the conversations in the texts by either underlining the feature or stating them orally.

In the fourth and fifth sessions, the focus of instruction was on teaching of the second main feature of spoke grammar, i.e. tails. These sessions proceeded similarly to what had happened in the two first sessions. Afterwards, learners were instructed on the two remaining features of progressive past tense and ellipsis in sessions 6,7 and 8,9 respectively with each pair of sessions focusing first on one feature and then a brief review of the preceding sessions. As mentioned previously, the focus on each of the sessions was to fully comprehend the instructed features so that the participants could recognize the features when they encountered them in similar contexts.

Session 10, as the last session of treatment, was dedicated to reviewing of all features taught. All sessions were of 90 minutes duration. After the last session, a post- test was administered, the results of which needed to be compared with those of the pre- test to see investigate any probable difference between participants' awareness of the features prior to and after the treatment.

\subsection{Design}

In line with the mainstream practice in the field, and because of inherent difficulty to use true experimental design, the present study was quasi experimental in nature. All of the participants were assigned to one experimental group. Therefore the design of the present study was one group, pre-test, post-test.

\section{Data Processing and Analysis}

The data collected through pre- and post-tests were analyzed by the Statistical Package for Social Science [SPSS] version 18. The data obtained were in the form of both numbers, 


\section{Macrothink}

Global Journal of Educational Studies

ISSN 2377-3936

2017, Vol. 3, No. 1

referred to as frequencies, and also scores. That is, the number of feature heads, for instance, identified correctly by participants in the pre- test was considered as the frequency of heads identified in the pre- test. The other format of the collected data was in the form of scores. As the performance of participants in the pre- test in terms of their mean scores were to be compared with their performance in the post- test, a paired samples t- test was conducted to ascertain whether the instruction had been statistically effective in raising their awareness of the above-mentioned features or not. To achieve a statistical significance, the alpha level was set at 0.05 .

\section{Results}

In order to address the research question about whether or not the explicit instruction of spoken grammar features of heads, tails, progressive past tense, and ellipsis had any significant effect on raising learner's awareness of these features, a standard proficiency test was administered initially to ensure the homogeneity of the participants. The first part of data analysis tested the difference in proficiency levels of the participants in the experimental group. Table 1 displays the descriptive statistics of the participants' scores on KET test.

Table 1. Descriptive statistics of the proficiency test (KET)

\begin{tabular}{|l|c|c|c|c|c|c|c|c|c|}
\hline & $\mathrm{N}$ & Min & Max & Mean & SD & \multicolumn{2}{|c|}{ Skewness } & \multicolumn{2}{|c|}{ Kurtosis } \\
\cline { 2 - 10 } & & & & & & & Std. Error & & Std. Error \\
\hline KET Scores & 23 & 54 & 87 & 72.26 & 8.83 & -.675 & .481 & .286 & .935 \\
\hline Valid N (listwise) & 23 & & & & & & & & \\
\hline
\end{tabular}

Table 1 shows that 23 participants taking the proficiency test had the mean score of 72.26 and the standard deviation of 8.83. The minimum score was 54 and the maximum was 87 . The skewness statistic indicates that the data is normality distributed. This skewness value needs to be within the range of plus and minus 1.96 to ensure the homogeneity of the participants. In our case the value is 0.675 . The positive value for kurtosis is 0.2.86 which means the distribution is rather peaked with long thin tails. This is further confirmed by the curve shown on the histogram in Figure 1: 


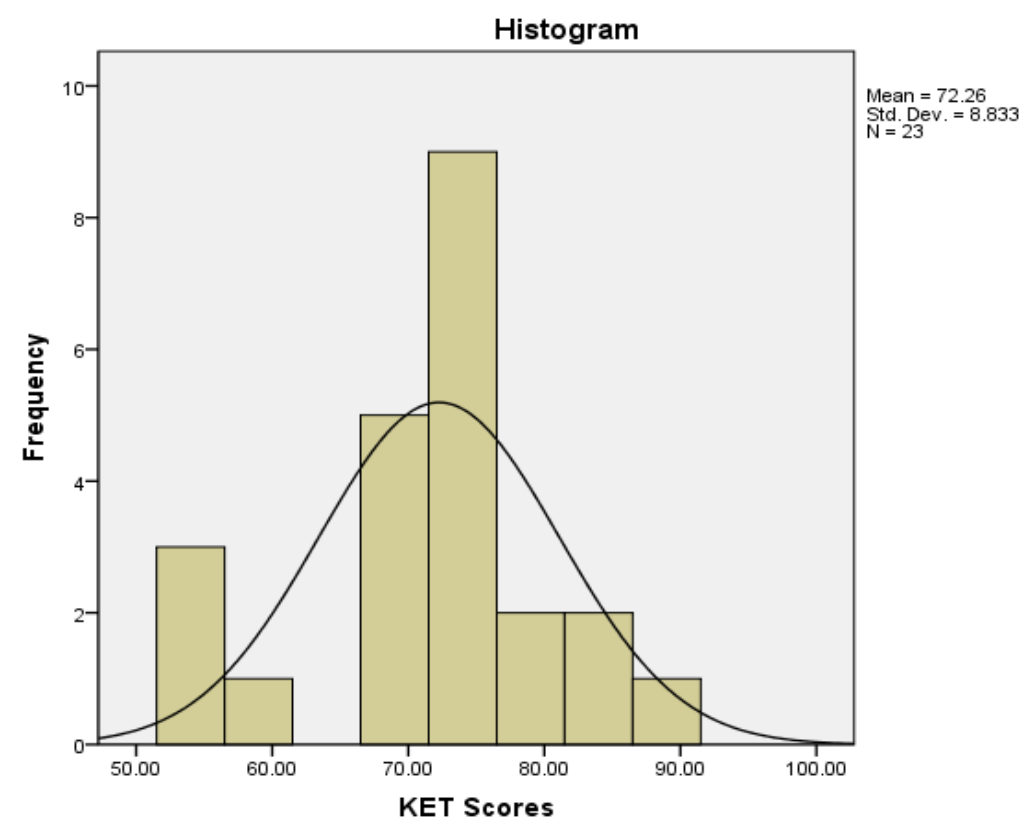

Figure 1. Histogram of the scores of the KET administration

As shown in Figure 1, the distribution of data in the participants' scores on KET proficiency test is normal and the graph is substantially bell- shaped with a peak.

To answer the research question and verify the related null hypothesis of the study, regarding the effect of explicit instruction on Iranian EFL learners' awareness of spoken grammar features, the researchers first conducted a paired t-test to see whether the mean score of the participants in terms of the frequency of the correctly identified features changed and, if so, whether the change was statistically significant. The result is shown in Table 2.

Table 2. Total number of features correctly identified in Pre-Test and Post-Test

\begin{tabular}{|l|c|c|c|c|}
\hline & Number of Heads & Number of Tails & $\begin{array}{c}\text { Number of Progressive } \\
\text { Past Tenses }\end{array}$ & Number of Ellipses \\
\hline Pre- Test & 44 (out of 161) & 42 (out of 184) & 81 (out of 184) & 42 (out of 161) \\
\hline Post- Test & 151 (out of 161) & 154 (out of 184) & 161 (out of 184) & 131 (out of 161) \\
\hline
\end{tabular}

a. Limited to first 100 cases.

Even a cursory look at the above table shows the magnitude of difference between participants' performance in pre- and post- test. As Table 2 displays, the total number of heads correctly identified by participants is 44 for pre- and 151 for the post- test which indicates a sharp rise. This number for tails correctly identified in the pre-test was 42 which rose dramatically to 154 in post- test. The third result is about progressive past tense which was identified correctly 81 times in the pre-test and once again the figure rose to 161 in the 
post-test. Finally, the frequency of correctly detected ellipses was 42 in pre- and 131 in the post test which is an indication of remarkable rise between the two. Although frequencies can tell us a great deal about the learners' awareness of the features before and after the treatment, in order to be on the safe side, we have to refer to the total scores obtained on pre- and post-test and then to compare the means so that our findings can be confirmed.

Table 3. Descriptive statistics of scores on Pre- and Post-Test

\begin{tabular}{|l|c|c|c|c|c|c|}
\hline & N & Min & Max & \multicolumn{2}{|c|}{ Mean } & SD \\
\hline Pre-test Score & 23 & 1 & 18 & 8.82 & .769 & 3.688 \\
\hline Post-test Score & 23 & 21 & 29 & 25.95 & .437 & 2.099 \\
\hline Valid N (listwise) & 23 & & & & & \\
\hline
\end{tabular}

The data indicates that the mean score of the 23 test takers on the pre-test is 8.82 which seems to be very low in comparison with their mean score on the post- test which is 25.95. Thus, the participants seem to have improved dramatically in terms of awareness raising. However, in order to make sure whether this means are statistically different a pairedsamples t- test was conducted to compare the results. Table 4 displays the outcome of the test.

Table 4. Paired samples T- Test

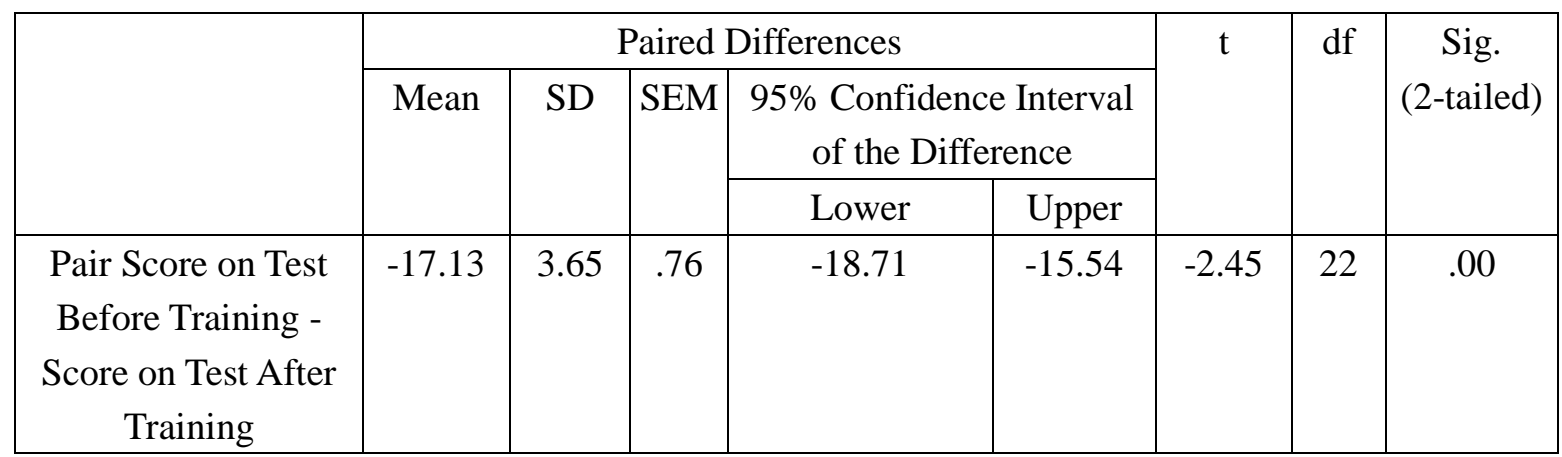

As displayed on the paired samples t-test in Table 4, the participants performed statistically differently on their posttest compared to the pretest. Therefore, as the significance level is .000 which is below 0.5, the null hypothesis "Explicit instruction of spoken grammar features of heads, tails, progressive past tense and ellipsis has no effect on raising Iranian EFL learners' awareness of these features at pre- intermediate level" is rejected. It can be concluded that 'explicit instruction' had had statistically significant effect on raising preintermediate EFL learners' awareness of the above- mentioned features in that, previously the learners were substantially unaware of these mostly ignored features in their textbooks.

\section{Discussion}

The result of the present study clearly shows that explicit instruction has statistically 
significant effect on raising pre-intermediate EFL learners' awareness about the grammatical features of interest. These findings seem to be generally in line with the consensus that explicit instruction can lead to raising awareness by means of which learning language features is substantially facilitated (Ellis, 1997).

The result of the current study seems to be in line with the results of a number of studies on the positive effect of explicit instruction on students' awareness of other linguistic features. For instance, Shmidt (1994), Chavarria and Bonany (2006), Kondo (2004) and Rose (1994) found that explicit instruction positively affects and raises learners' awareness of English language properties.

Support from Schmidt (1994) is based on his assertion that learning aspects of a second language is not possible through subliminal learning and that, if learners are to learn a feature or an aspect, they should consciously notice. He further notes, 'this requirement of noticing is meant to apply to all aspects of language such as lexicon, phonology, grammatical form and pragmatics', and that it may be essential for adults to pay attention to language forms in order to acquire superfluous grammatical features (p. 149). He proposes that explicit instruction may play a significant role in making learners notice features they do not come to notice otherwise. The result of this present study seems to be not only in line with Schmidt's notion, but also with the findings of a number of other studies on the effect of awareness on learning. For instance, Chen (2008) found a significant effect of awareness on the learning of English structures and advocated the necessity of having an explicitly instructional approach was felt. Further support comes from another study by Haiying and Manchun (2004) on explicit/implicit instruction of English relative clauses. The results show that, although explicit teaching is not sufficient for having a perfect knowledge system, it helps improve linguistic knowledge, grammatical judgment and performance. This concurred with Kondo's (2004) findings in which Japanese learners' pragmatic awareness of refusal increased as a result of receiving explicit instruction on this feature. This agreement is important because pragmatic awareness can be considered as another feature associated with a face to face interactional context (Mey, 2001), a feature which can be assumed to be absent in the EFL context of Japan. However, in this case too, explicit instruction had its role in raising Japanese EFL learners' awareness of this feature. In a similar line of enquiry, Rose (1994) points out that one of the approaches that can be used for teaching pragmatics is awarenessraising. This observation is also in accordance with what Timmis (2005) has put forward. He considers the positive effect of explicit instruction and awareness raising. In his study, Timmis designed a syllabus in which learners' awareness of spoken language was raised by means of designed materials and explicit instruction of them. This notion is in line with what Ellis (1997) states about explicit instruction in that it can draw learners' attention to items they may not notice otherwise.

What sets the present study apart was the fact that it investigated the effect of explicit instruction of spoken grammar features of heads, tails, progressive past tense and ellipsis on raising learners' awareness of these properties in the EFL context where, by definition, the occurrence of these features is minimal, if any at all, in a naturalistic setting. Accordingly, a corollary which can be drawn is that each of these oral grammatical points could be acquired 


\section{Mll Macrothink}

Global Journal of Educational Studies

ISSN 2377-3936

2017, Vol. 3, No. 1

inductively through learners' extensive exposure to high occurrence frequency of these features in natural setting, a condition which does not seem to be present in a foreign language context like Iran where it is highly unlikely for the learners to encounter and learn spoken grammar features such as heads, tails, progressive past tense and ellipsis unconsciously. The results show that the balance can be redressed to some extent through explicit instruction of these features, thus raising learners' consciousness of these features if not leading them to acquire them thoroughly,. It is postulated that EFL learners mostly need to be made aware of existing language features before being able to assimilate them to be used in their own spoken English.

The findings indicate that the effect is powerful enough to be taken seriously in this case, a result which can complement and fill the gap with the aforementioned studies on the effect of explicit instruction on various linguistic features, in that oral grammar as well as the written one is amenable to explicit instruction. The importance of explicit learning can be highlighted by the fact that, in a foreign language context like Iran, it gains more significance due to the restricted access to the authentic material occurring in an actual context. Therefore, explicit instruction and consciousness raising might tip the balance in the favor of this neglected aspect. Therefore, explicit instruction can raise EFL learners' awareness on spoken grammar and enhance their performance in this regards which makes it a worthwhile effort in the era of communicative language teaching.

The significance of communicative language teaching and learning is reflected by Timmis (2003) in that if spoken grammar teaching is to flourish, it is obviously important that teachers acquire the descriptive terminology and declarative knowledge to explain certain features of spoken grammar. It is not simply a question of terminology, of course, it also requires teachers to re-assess what grammar is. In some cases there even might be a need for a quite radical re-assessment. Timmis argues, at a time when communicative methodologies still lead the field of English, the study of spoken language should form a part of all teacher training courses, including short pre-service courses; since teachers will be able to help learners notice what they themselves have noticed in the course of dealing with texts for different purposes.

If teaching of spoken language is to develop, it will be important that the value of developing sensitivity to language use and variation, more than that of teaching any particular language features, is more widely recognized. According to Timmis (2003) our approach is about more than importing 'broken English' into classrooms. It is about investigating how native speakers communicate, an investigation which requires reflection on the nature of grammar and the nature of effective communication. The result of the present study indicates that raising EFL learners can be conducive to achieving this purpose.

\section{References}

Bialystok, E. (1978). A theoretical model of second language learning. Language Learning, 28, 69-84. https://doi.org/10.1111/j.1467-1770.1978.tb00305.x

Biber, D., Johansson, S., Leech, G., Conrad, S., Finegan, E., \& Quirk, R. (1999). Longman 
grammar of spoken and written English (Vol. 2). MIT Press.

Carter, R. (1998). Orders of reality: CANCODE, communication, and culture. ELT Journal, 52(1), 43-56. https://doi.org/10.1093/elt/52.1.43

Carter, R., \& McCarthy, M. (1995). Grammar and the spoken language. Applied Lnguistics, 16(2), 141-158. https://doi.org/10.1093/applin/16.2.141

Carter, R., \& McCarthy, M. (1997). Exploring Spoken English (Vol. 2). Cambridge: Cambridge University Press.

Carter, R., Hughes, R., \& McCarthy, M. (1998). Telling tales: Grammar, the spoken language and materials development. In Tomlinson (Ed.), Materials development in language teaching (pp. 67-86). Cambridge: Cambridge University Press.

Chavarría, M. I., \& Bonany, E. B. (2006). Raising awareness of pragmatics in the EFL classroom: A proposal. Cultura, Lenguaje y Representación: Revista de Estudios Culturales de la Universitat Jaume I, 3, 133-144.

Chen, Q. (2008). The role of awareness in Chinese students' learning of English prepositional structure. CELEA Journal, 31(6), 63-71.

Cullen, R., \& Kuo, I. (2007). Spoken grammar and ELT course materials: A missing link? Tesol Quarterly, 41(2), 361-386. https://doi.org/10.1002/j.1545-7249.2007.tb00063.x

Ellis, R. (1994). The study of second language acquisition. Oxford: Oxford University Press.

Ellis, R. (1997). Second language acquisition. Oxford: Oxford University Press. https://doi.org/10.1515/9783110292022-020

Fotos, S. S. (1994). Integrating grammar instruction and communicative language use through grammar consciousness-raising tasks. TESOL Quarterly, 323-351. https://doi.org/10.2307/3587436

Haiying, G., \& Manchun, D. (2004). The acquisition of relative clause extraposition by Chinese learners of English: A study of the effects of explicit/implicit instruction. Foreign Language Teaching and Research, 6, 006.

Kondo, S. (2004). Raising pragmatic awareness in the EFL context. Sophia Junior College Faculty Bulletin, 24, 4972.

Krashen, S. (1985). The Input Hypothesis: Issues and Implications. London: Longman.

McCarthy, M. (1998). Spoken language and applied linguistics. Cambridge: Cambridge University Press.

McCarthy, M., \& Carter, R. (1995). Spoken grammar: What is it and how can we teach it? ELT Journal, 49(3), 207-218.

Mey, J. L. (2001). Pragmatics: An introduction (2nd ed.). Wiley Blackwell.

Paterson, K., Caygill, C., \& Sewell, R. (2012). A handbook of spoken grammar. Delta 
Publishing.

Schmidt, R. (1990). The role of consciousness in second language learning. Applied Linguistics, 11(2), 129-158. https://doi.org/10.1093/applin/11.2.129

Schmidt, R. (1994). Implicit learning and the cognitive unconscious: Of artificial grammars and SLA. In N. Ellis (Ed.), Implicit and explicit learning of languages, 22, 165-209. London: Academic Press.

Sharwood, S. M. (1981). Consciousness-raising and the second language learner. Applied Linguistics, 2, 159-68. https://doi.org/10.1093/applin/2.2.159

Swan, M. (1995). Practical English usage. Oxford: Oxford University Press.

Timmis, I. (2003). Corpora, classroom and context: The place of spoken Grammar in English language teaching (Doctoral dissertation, University of Nottingham). Pedagogy. ELT Journal, $55(3), 238-246$.

Timmis, I. (2005). Towards a framework for teaching spoken grammar. ELT Journal, 59(2), 117-125. https://doi.org/10.1093/eltj/cci025

Willis, D. (2003). Rules, patterns and words: Grammar and lexis in English language teaching. Cambridge: Cambridge University Press. https://doi.org/10.1017/CBO9780511733000

\section{Appendix}

\section{Pretest/ Posttest}

Name:

Level:

Time: $30 \mathrm{~min}$.

Consider the definitions of spoken grammar features of heads, tails, use of past continuous to report speech and ellipsis as follow:

Heads: In conversation, we can sometimes change the regular order of words to put emphasis on particular parts of the sentence. By 'heads' we mean things we take from their normal place and put at the front of sentences.

Tails: In conversation, we can sometimes change the regular order of words to put emphasis on particular parts of the sentence. 'Tails' are things we take from their normal place and put at the end of sentences.

Use of past continuous: In conversation, we sometimes use the past continuous to report recent conversations.

Ellipsis (saying less): Ellipsis means leaving out (not saying) words when your meaning is 


\section{Macrothink}

Global Journal of Educational Studies

ISSN 2377-3936

2017, Vol. 3, No. 1

clear without them. It is a natural part of conversation, not only because it saves time, but also because it 'links' what we say to what our partner has said.

According to the above- mentioned definitions, try to identify and underline heads, tails, past continuous which report speech and ellipsis in the following dialogue between two friends.

Amy: Thank goodness they've finally gone! It's two in the morning.

70

Tom: What a mess! Is it yours? the red bag in the corner.

Amy: Oh, no! Someone's left it. The girl with the tall boyfriend, do you know her name? I was telling John about her and he said it was hers, the bag.

Tom: She'll ring us, won't she? Anyway, we'd better start clearing up. Are they all empty? those bottles on the table.

Amy: Yes. They can be recycled.

Tom: I'm getting tired. How about going somewhere?

Amy: The new French restaurant on Park Street, does it sound good?

Tom's cellphone rings.

Tom's friend: Hi. It's Jeff. Feeling ok?

Tom: Got a headache again, I'm afraid. Where are you?

Tom's friend: on the train.

Tom: The match last night, what was the score?

Tom's friend: 2-2. They drew.

Tom's friend: Magi was telling me about your new trainers, did you find them?

Tom: unfortunately not.

Tom's friend: Not a big deal, Tom. You know what? They're getting married, Olivia and Jack. All people in the party were talking highly of them. They said they would make a nice couple.

Tom: So I heard.

Tom's friend: I got no more news to share, then!

Tom: I really miss you, Jeff. Hope to see you soon.

Tom's friend: I Hope so.

Tom and Mary are in a restaurant now.

Tom: These sardines, they're rather good. Yesterday John was telling me about the sardines 


\section{Macrothink \\ Global Journal of Educational Studies \\ ISSN 2377-3936 2017, Vol. 3, No. 1}

they'd caught. He said they were so delicious. How's your dish?

Mary: Actually, I'm not very hungry. I'm feeling a bit tense.

Tom: Well, this is your chance to relax, this meal with me. Ravi was talking about your sister. I know you're worrying about your sister again. But try to be positive. She'll be ok, Sophie will.

Amy: I hope so.

Tom: Anyway, I was telling Chris about my trip to Colombia and he said he was planning to go there in the summer.

Mary: That's perfect. I'm planning to go there too!

Tom: Let's go, Amy. We're gonna be late. The white coat, is it yours?

Mary: No, mine's pink.

Tom: Ok, then. Hurry up.

In parts 1, 2, 3 and 4, which of the sentences, regarding the features taught, are possible in spoken English'? There is more than one correct answer.

1.

a. The children, they demand breakfast.

b. They demand breakfast, the children.

c. The children demand breakfast, they.

d. The children demand, they, breakfast.

2.

a. John is a good man.

b. He's a good man, John.

c. John's a good man, John.

d. John, he's a good man

3.

a. Do you want to go there?

b. Wanna go there?

c. You wanna go there?

d. Go there, wanna?

4). Which of the following sentences are examples of reported speech? There is more than one correct answer. 


\section{Macrothink \\ Global Journal of Educational Studies \\ ISSN 2377-3936 2017, Vol. 3, No. 1}
a. She was saying bad words to his mom.
b. He was telling me about the last year's war.
c. She was asking the teacher a lot of questions.
d. He was talking about the party last night.
e. She was saying she didn't feel well.

\section{Copyright Disclaimer}

Copyright for this article is retained by the author(s), with first publication rights granted to the journal.

This is an open-access article distributed under the terms and conditions of the Creative Commons Attribution license (http://creativecommons.org/licenses/by/3.0/). 